\title{
Blood Pressure Monitoring
}

1.12 Role of Trained Nurses in the Blood Pressure Control of Treated Essential Hypertensive Patients

G. Leotta, F. Rabbia, M Mulone, C. Modica, E. Testa, S. Monticone, E. Saglio,

C. Magnino, A. Viola, F. Tosello, G. Papotti, C. Paglieri, F. Veglio

Department of Hypertension and Internal Medicine, University of Turin,

Turin, Italy

Introduction: When measuring BP, the physician induces a transient pressor response triggered by an alarm reaction. This 'white-coat effect' can influence therapeutic decisions.

Objective: To assess the difference of blood pressure measured by physician, nurse and by patients at home.

Methods: 100 patients were selected from those referred to a hypertension clinic. they had had their supine systolic/diastolic blood pressure measured firstly by a trained nurse (mean of the last two of three measurements taken every 2 min by an oscillometric device) and then by a physician (auscultatory method using a standard mercury sphygmomanometer). The patients measured their home BP (one reading in the morning and one reading in the evening for 5 continuous days). Moreover, the patients completed a questionnaire in order to test if the nurse pre-evaluation can reduce the degree of anxiety in the patient.

Results: The mean systolic/diastolic blood pressure for physicians was $149 \pm 11 / 89 \pm 12 \mathrm{mmHg}$, that for the nurse was $144 \pm 11 / 85 \pm 8 \mathrm{mmHg}$ and for Home $139 \pm 12 / 85 \pm 10 \mathrm{mmHg}$. 